\title{
Reserves and exposure assessment of reinforced concrete structures safety while reducing its power resistance
}

\author{
Ekaterina Kuzina ${ }^{1, *}$, Vladimir Rimshin ${ }^{2}$, and Alexey Neverov ${ }^{1}$ \\ ${ }^{1}$ Research Institute of Building Physics of the Russian Academy of Architecture and Building \\ Sciences (NIISF RAASN), 127238, 21, Locomotive passage, Moscow, Russia \\ ${ }^{2}$ Moscow State University of Civil Engineering (MGSU), 129337, 26, Yaroslavskoye Shosse, \\ Moscow, Russia
}

\begin{abstract}
Structural safety of buildings is such an engineering state of the structures operability, foundations, the features of their joint power resistance to expected loads and impacts, taking into account their possible combinations in direction, intensity and mode, which ensures the established functional use with established reliability. The structural safety of buildings depends on design, on compositional and structural solutions, technological measures during construction and operation, which must be provided at all stages of the facility's existence (construction, operation, repair, reconstruction, dismantling and dismantling). It is necessary to take into account the structural safety parameters of reinforced concrete structures that have received corrosion damage during solving the problems of construction and reconstruction of buildings and structures. Suggestions to quantify the reserves and exposure of structural safety and, accordingly, the reduction in power resistance of corrosion-damaged reinforced concrete structures are presented in this article.
\end{abstract}

\section{Introduction}

The structural safety of buildings interests requires ensuring: geometric invariability of the structural scheme at all the stages of their existence (and during reconstruction and dismantling - with the additional connections help), a stable stress-strain state and position in space and time of all supporting structures of the building, and survivability of statically indefinite systems. And yet, the common thing is to ensure the strength and stability of individual load-bearing elements of the system and the so-called «redundant ties» despite the different purpose of these conditions [1-9]. At the same time, the assessment of structural safety is an obligatory stage of the decision-making procedure on the issues of continued operation or technological reorganization of production, reconstruction, etc. (it is carried out only on the basis of a field examination).

*Corresponding author: kkuzzina@mail.ru 


\section{Materials and methods}

However, the existing regulated approach for solving structural safety problems is almost always limited to the equilibrium (or pseudo-equilibrium) statement, and other analysis options are replaced by a set of so-called working condition coefficients and does not provide answers to questions of changes in power resistance (including the question of structural safety exposure) related to energy dissipation during deformation and due to corrosion damage to structural materials due to aggressive action of the medium dy. In general, the task boils down to taking into account the energy imperfections in the strength resistance of materials and the irreversible accumulation of damage, to identifying the key elements of the system responsible for geometric immutability, kinetic stability and survivability. The analysis of the power state and the forecast of its change in the billing period exhaust the main questions about the potential and exposure of constructive safety [10-15].

Power resistance residual resource of compressed reinforced concrete elements in terms of stability. The base case for estimating the power resistance residual resource of eccentrically compressed reinforced concrete elements is a supported rod loaded with compressive force with an eccentricity $e_{0}$. The diagram of an eccentrically compressed reinforced concrete rod and a graph of the compressive force and max deflection $\mathrm{f}^{*}$ are shown in Figure 1.
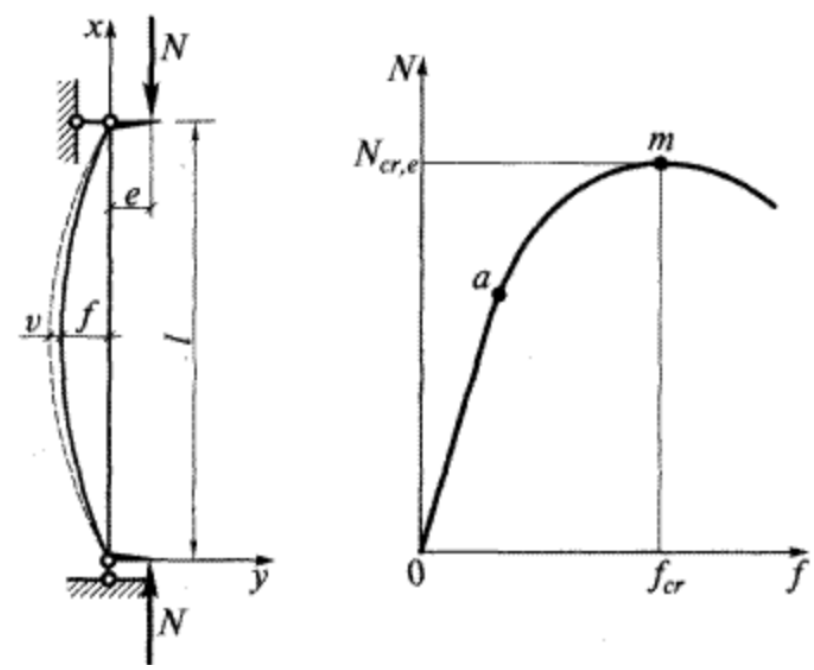

Fig. 1. The scheme of an eccentrically compressed reinforced concrete bar and a connection graph of compressive force and max deflection $\mathrm{f}^{*}$.

The problem is solved in a physically nonlinear formulation. The condition for the sufficiency of power resistance is:

$$
\mathrm{P} \leq \mathrm{P}^{*}
$$

It should be noted that the initial eccentricity can vary due to damage to the cross sections, as a rule, it increases slightly.

For the given case (see Figure 1):

$$
\left.\begin{array}{c}
D * \frac{d^{2} u}{d V^{2}}=-M \\
M=P\left(e_{0}^{*}+u\right)
\end{array}\right\}
$$

Thus 


$$
D \cdot \frac{d^{2} u}{d V^{2}}+P\left(e_{0}^{*}+u^{*}\right)=0
$$

where $\mathrm{P}$ - external compressive force;

$e_{0}^{*}$ - initial eccentricity taking into account the damage;

$\mathrm{u}^{*}$ - current deflection of the rod.

After double differentiation, it is obtained that

$$
\frac{d^{2}}{d V^{2}} D \cdot \frac{d^{2} u}{d V^{2}}+P \frac{d^{2} u}{d V^{2}}=0
$$

And then, using the principle of possible displacements and satisfying the static boundary conditions of the corresponding variational equation, it should be brought the desired solution to the relation by N. G. Bubnov-B.G. Galerkin [16-18]:

$$
\int_{\delta}^{\epsilon_{0}}\left[\frac{d^{2}}{d V^{2}} D \cdot \frac{d^{2} u}{d V^{2}}+P \frac{d^{2} u}{d V^{2}}\right] \delta u d V=0
$$

Further accepting

$$
\mathrm{u}=\sum_{\mathrm{i}=1}^{\mathrm{i}=1} \mathrm{f}_{\mathrm{i}}^{*} \eta_{\mathrm{i}} ; \delta \mathrm{u}=\sum_{\mathrm{i}=1}^{\mathrm{i}=1} \mathrm{f}_{\mathrm{i}}^{*} \delta \eta_{\mathrm{i}}
$$

where $\delta \mathrm{f}^{*}$ - independent variation of deflection parameters, and limited for practical purposes to the first members of the series

$$
\eta=\sin \frac{\pi \mathrm{V}}{\mathrm{l}_{0}} ; \mathrm{u}=\mathrm{f}^{*} \sin \frac{\pi \mathrm{V}}{1}
$$

where $\eta$ - satisfies the boundary conditions, the resolving equation of the problem:

$$
\int_{0}^{e_{0}}\left[-D^{*} f^{*}\left(\frac{\pi}{1_{0}}\right)^{2} \sin \frac{\pi V}{1_{0}}+P^{*}\left(e_{0}+f^{*} \sin \frac{\pi V}{1_{0}}\right)\right] \sin \frac{\pi V}{1_{0}} d V=0
$$

Solving the equation gives the relationship between the compressive force $\mathrm{P}^{*}$ and the deflection $\mathrm{f}^{*}$ (see Figure 1), and the well-known procedure for finding the extremum is the desired values $\mathrm{f}_{\mathrm{kp}}^{*}$ and $\mathrm{P}_{\mathrm{kp}}^{*}$.

$$
\left(\mathrm{R}_{\mathrm{kp}}\right)^{*}=\mathrm{Q}\left(\mathrm{p}_{\mathrm{eil}}^{0}\right)^{*}
$$

where

$$
\begin{aligned}
& \left(\mathrm{p}_{\mathrm{eil}}^{0}\right)^{*}=\left(\frac{\pi}{\mathrm{I}_{0}}\right)^{2} \mathrm{D}_{\text {max }}^{*} \\
& \mathrm{Q}=\frac{1}{\mathrm{a}_{0}+\frac{2_{1}}{\mathrm{f}_{\mathrm{kp}}}+\mathrm{a}_{2} \mathrm{f}_{\mathrm{kp}}^{*}} \\
& \mathrm{a}_{0}=\frac{\left(\mathrm{p}_{\mathrm{eil}}^{0}\right)^{-}-\left(\mathrm{p}_{\mathrm{eil}}^{\mathrm{np}}\right)^{*}}{\mathrm{M}_{\mathrm{np}}} \\
& \mathrm{a}_{2}=\frac{8\left[\left(\mathrm{p}_{\mathrm{eil}}^{0}\right)^{*}-\left(\mathrm{p}_{\mathrm{eil}}^{\mathrm{np}}\right)^{*}\right]}{\mathrm{M}_{\mathrm{np}}^{*}}
\end{aligned}
$$




$$
\mathrm{f}_{\mathrm{kp}}^{*}=\frac{1_{0}}{\pi} \sqrt{\frac{3}{2} \frac{\left(\mathrm{M}_{\mathrm{np}}^{*}\right) \epsilon_{0}}{\left(\mathrm{D}_{\max }^{*}-\mathrm{D}_{\min }^{*}\right)}}
$$

And also set the free rotation angle of the rod cross section at the hinge support

$$
\varphi_{\mathrm{kp}}^{*} \approx \sqrt{\frac{3}{2} \frac{\mathrm{M}_{\mathrm{np}}^{*} \mathrm{e}_{0}}{\left(\mathrm{D}_{\max }^{*}-\mathrm{D}_{\min }^{*}\right)}}
$$

and

$$
\mathrm{e}_{0}=\frac{\mathrm{M}_{\mathrm{np}}^{-}}{\mathrm{p}}\left(1-\frac{\mathrm{p}}{\mathrm{p}_{\mathrm{np}}^{*}}\right)
$$

The transition from the base case (see Figure 1) to other fixing conditions is quite accurately carried out using the factor of the calculated length $\mu_{\mathrm{k}}$, established in the classical theory of materials resistance (Figure 2).

$$
\mathrm{l}_{0, \mathrm{k}}=\mu_{\mathrm{k}} \mathrm{l}
$$

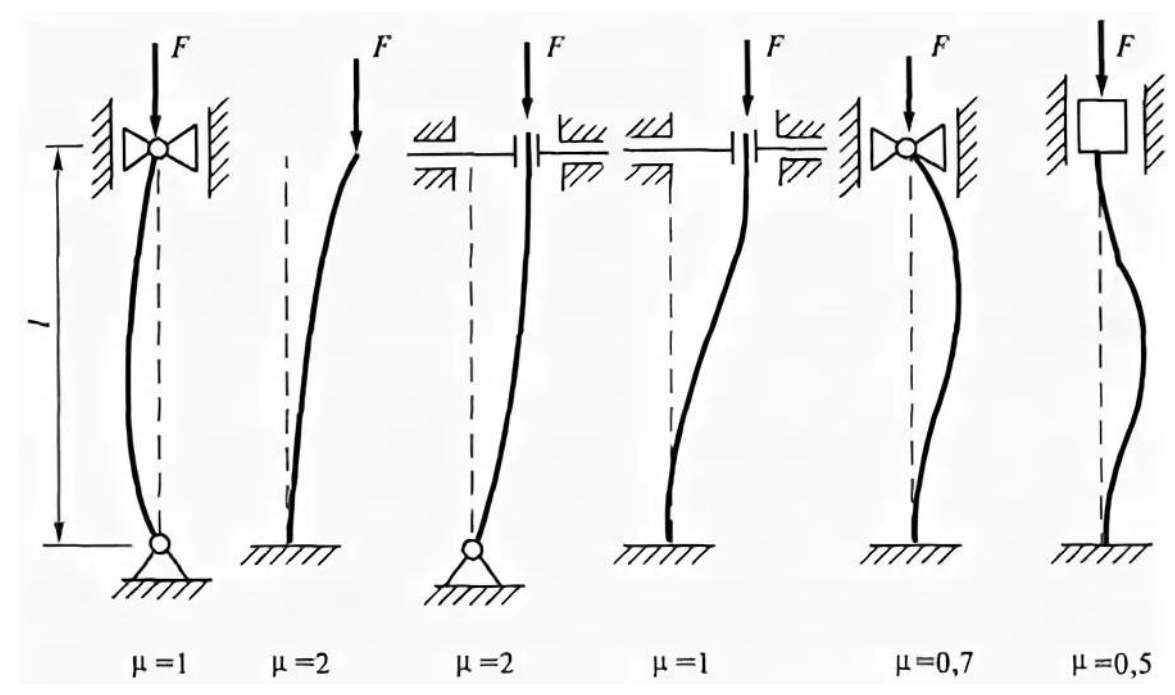

Fig. 2. The coefficient of the reduced length for compressed rods with various methods of ends fastening.

And

$$
\mathrm{P}_{\mathrm{cr} \cdot \mathrm{K}}^{*}=\frac{\mathrm{Q}\left(\mathrm{e}_{0} \mathrm{f}_{\mathrm{np}}\right)}{\left(\mu_{\mathrm{k}}\right)^{2}}\left(\frac{\pi}{1}\right)^{2} \mathrm{D}_{\max }^{*}
$$

Where $Q\left(e_{0}, f_{n p}^{*}\right)$ - reflects the influence of eccentricity and the range of changes in stiffness, i.e. deformation nonlinearity;

$\mathrm{D}_{\max }^{*}$ - damage to sections, as well as their change in time and depending on the mode and duration of loading;

$\mu_{\mathrm{K}}$ - the influence of boundary conditions.

The damage effect to the support nodes of beams and columns on the power resistance. The effect of node damage (changes in boundary conditions) is illustrated on the main elements of building frames - beams and columns [17-25]. 
A. Two identical single-span beams are compared with a span of $1 \mathrm{~m}$, but with different boundary conditions; in particular, the B-1 beam, pinched on the supports and loaded with a uniform $\mathrm{q}=$ const, and the B-2 beam, pivotally supported on the supports and loaded with the same uniform load $\mathrm{q}=$ const. The beam B-1 bending moments in pinching equal:

$$
\mathrm{M}_{\min }=-\frac{\mathrm{ql}^{2}}{16}
$$

mid-span

$$
\mathrm{M}_{\max }=\frac{\mathrm{ql}^{2}}{16}
$$

and the angle of the reference section rotation is zero.

The beam B-2 bending moments are described by the equation

$$
\mathrm{M}=\frac{\mathrm{qv}(\mathrm{l}-\mathrm{v})}{2}
$$

which leads to the calculation of the reference moments

$$
\mathrm{M}_{\min }=0
$$

and mid-span moments

$$
\mathrm{M}_{\max }=\frac{\mathrm{ql}^{2}}{8}
$$

wherein the angle of the reference section free rotation

$$
\varphi_{0}=\frac{q 1^{3}}{2^{3} \cdot 3 D_{\max }^{*}}+\frac{q^{2} 1^{5}}{2^{4} 3^{5} M_{\mathrm{cr}}^{*}}\left(\frac{1}{D_{\min }^{*}}-\frac{1}{D_{\max }^{*}}\right)
$$

It follows that the beam B-1 without destruction can perceive as a uniform load

$$
\mathrm{q}=2 \frac{8 \mathrm{M}_{\mathrm{cr}}}{1^{2}}
$$

and beam B-2, respectively

$$
\mathrm{q}=\frac{8 \mathrm{M}_{\mathrm{cr}}}{1^{2}}
$$

that is half as much.

Thus, if the B-1 beam will lose the ability to perceive the supporting moments due to damage to the supporting sections, and the beam itself will receive an articulated design scheme, then the resource of its bearing capacity will be reduced by half.

At intermediate stages, when the supporting sections of the B-1 beam are partially damaged while maintaining a certain fraction of the power resistance, the supporting moments are partially perceived and the sections themselves receive some rotation $\varphi_{1}^{*}>0$. Next, the maximum allowable load is calculated.

$$
q^{*}=q_{2}+\frac{\left(\varphi_{\max }-\varphi_{1}\right)}{\varphi_{\max }}\left(q_{1}-q_{2}\right)
$$

and correspondingly

$$
\frac{q^{*}}{q_{1}}=\frac{\left(\varphi_{\max }-\varphi_{1}\right)}{\varphi_{\max }}+\left(1-\frac{\left(\varphi_{\max }-\varphi_{1}\right)}{\varphi_{\max }}\right) \frac{q_{2}}{q_{1}}
$$


or

$$
\mathrm{q}^{*}=\frac{\left(\varphi_{\max }-\varphi_{1}\right)}{\varphi_{\max }} \mathrm{q}_{1}+\left(1-\frac{\left(\varphi_{\max }-\varphi_{1}\right)}{\varphi_{\max }}\right) \mathrm{q}_{2}
$$

B. Damaged identical columns with various supporting anchors are considered.

So, in particular, during the transition from scheme 3 to scheme 1, which is typical for single-story industrial buildings, critical forces decrease by 2 times, and from scheme 3 to scheme 6 - by 8 times.

And given that the stiffness of the cross section can be reduced by 2 times, the total drop in strength resistance in stability decreases by 16 times.

Meanwhile, even a twofold decrease in power resistance is catastrophic [26-27]. In case of partial damage to the reference sections and corresponding changes in the rotation angles of these sections, the reduction coefficients are calculated by the formula

$$
\mu_{\mathrm{K}}^{*}=\mu_{\mathrm{K}}+\left(\mu_{1-} \mu_{\mathrm{K}}\right) \frac{\varphi_{\mathrm{K}}}{\varphi_{1}^{0}}
$$

\section{Results and discussion}

Quantitative assessment of structural safety and survivability of damaged operating structures. If during operation, the structural safety coefficient $K_{K, \delta}$ is equal to

$$
\begin{aligned}
& \mathrm{K}_{\mathrm{K}, \delta}=\frac{\mathrm{M}^{*}(\delta)}{\mathrm{M}_{0}} \geq\left[\mathrm{K}_{\mathrm{K}, \delta}\right] \\
& \mathrm{K}_{\mathrm{K}, \delta}=\frac{\mathrm{Q}^{*}(\delta)}{\mathrm{Q}_{0}} \geq\left[\mathrm{K}_{\mathrm{K}, \delta}\right] \\
& \mathrm{K}_{\mathrm{K}, \delta}=\frac{\mathrm{P}^{*}(\delta)}{\mathrm{P}_{0}} \geq\left[\mathrm{K}_{\mathrm{K}, \delta}\right]
\end{aligned}
$$

where $\left[K_{K, \delta}\right\rfloor$ is the structural safety coefficient specified during design, which should be from 1.8 to 2.2 , then it gradually decreases up to the value of $\mathrm{K}_{\mathrm{K}, \delta}=1.0$ during the period of evolutionary damage development and loss of the power resistance resource. The structure operation is prohibited when $\mathrm{K}_{\mathrm{K}, 8} \leq 1$,

At the moment of internal forces coincidence and force resistance, the reinforced concrete element is destroyed. The force resistance is equal to zero, which is equivalent to an impulsive application of a reverse sign force in the fracture cross section and equal in value to the previous residual force [28-30].

Since $\mathrm{K}_{\mathrm{K}, 8} \mathrm{depends}$ not only on the power resistance of the damaged structure $\left(\mathrm{M}^{*} \mathrm{Q}^{*}\right.$ и $\left.\left.\mathrm{P}^{*}\right),{ }^{*}\right)$, but also on the internal force, since it requires consistent correction, predetermined in statically indeterminate systems by redistribution of internal forces caused by non-synchronous development of damage to various structures. $M_{0}, Q_{0}, P_{0}, M^{*}, Q^{*}, P^{*}$.

Exposure to structural safety: $t_{\mathrm{y}}<\mathrm{t}_{\mathrm{cm}}<\mathrm{t}_{\mathrm{z}}$ - conditional, stable, delayed time.

Since, it is possible to determine the numerical value of the damage depth $\delta<x$ at the time of destruction using the formulas, then solution (2) with respect to $\left(t^{*}-t_{0}\right)$ - is the essence of the safety exposure, i.e., the survivability exposure.

For example, for $\mathrm{m}=1$

$$
t^{*}-t_{0}=-\frac{1}{\alpha} \ln \frac{\Delta \sigma_{p}}{\Delta \delta\left(t_{0}, t_{0}\right)}
$$


As mentioned above, due to the initial avalanche of damage $(\mathrm{m}<0)$, it is impossible to establish $\delta_{\mathrm{p}}$ and the estimation $\left(\mathrm{t}_{\mathrm{cr}}-\mathrm{t}_{\mathrm{o}}\right.$ ) is carried out at a certain critical speed, while it is considered that the critical speed is $\mathrm{n}$ times greater than the initial speed determined from experiments; then the calculation period $t_{\mathrm{cr}}-\mathrm{t}$ is calculated, i.e.

$$
\frac{d f_{m}\left(a, m, t, t_{0}\right)}{d t} \quad t=t_{e r}=n \frac{d f_{m}\left(a, m, t, t_{0}\right)}{d t} \quad t=t_{c r}
$$

Thus

$$
\left(t_{c r}-t\right)=\frac{1}{a(-m)+1}\left\{\left[(-1)^{\frac{n}{a}} \frac{d f_{m}}{d t} \mid t=t_{0}\right]^{\left[\frac{[(-m)+1]}{-(-m)}\right.}-1\right\}
$$

As noted above, such destruction of the reinforced concrete element is accompanied by a change in the static structure of the element [30-36].

\section{Conclusions}

The above suggestions make it possible to quantitatively assess the reserves and exposure of the reinforced concrete structures structural safety that have received corrosion damage, and, accordingly, the reduction in power resistance of corrosion-damaged reinforced concrete structures, which are necessary for solving the problem of using or reconstructing buildings and structures.

The developed method makes it possible to quantitatively assess the condition and resources of damaged reinforced concrete structures, calculate the necessary levels of compression and its loss, as well as the exposure to the preservation of crack resistance in time at a specific level of loading and the corrosion influences intensity.

The developed method can be presented as part of the solution to the problem of preventing and eliminating emergency situations.

\section{References}

1. V.T. Erofeev, A.D. Bogatov, V.F. Smirnov, S.N. Bogatova, V.I. Rimshin, V.L. Kurbatov, Bioresistant building composites on the basis of glass wastes. Bioscie. Biotech. Res. Asia, 12 (1), pp. 661-669 (2015)

2. V.M. Bondarenko, A.M. Kurzanov, V.I. Rimshin, The mechanism of seismic destruction of buildings (2000)

3. A.L. Krishan, V.I. Rimshin, M.A. Astafeva, Deformability of a Volume-Compressed Concrete. IOP Conf. Series: Mat. Scie. and Eng., 463 (2), № 022063 (2018)

4. A.A. Varlamov, V.I. Rimshin, S.Y. Tverskoi, The General theory of degradation. IOP Conf. Series: Mat. Scie. and Eng., 463 (2), № 022028 (2018)

5. A.I. Krishan, V.I. Rimshin, E.A. Troshkina, Strength of Short Concrete Filled Steel Tube columns of Annular Cross Section. IOP Conf. Ser.: Mat. Scie. and Eng., 463 (2), № 022062 (2018)

6. A..L. Krishan, M.Yu. Narkevich, A.I. Sagadatov, V.I. Rimshin, Experimental investigation of selection of warm mode for high-performance self-stressing selfcompacting concrete. IOP Conf. Series: Mat. Scie. and Eng., 456 (1), № 012049 (2018) 
7. A.A. Varlamov, V.I. Rimshin, S.Y. Tverskoi, Planning and management of urban environment using the models of degradation theory. IOP Conf. Series: Earth and Envir. Scie., 177 (1), № 012040 (2018)

8. V.I. Rimshin, B.V. Labudin, V.I. Melekhov, A. Orlov, V.L. Kurbatov, Improvement of strength and stiffness of components of main struts with foundation in wooden frame buildings. ARPN J. of Eng. and Appl. Scie., 13 (11), pp. 3851-3856 (2018)

9. V.I. Rimshin, A.A. Varlamov, Three-dimensional model of elastic behavior of the composite (2018)

10. V.I. Rimshin, A.A. Pudova, L.I. Shubin, Evaluation of efficiency of use of photoelectric systems at operation of a residential house (2018)

11. V. Telichenko, V. Rimshin, E. Kuzina, Methods for calculating the reinforcement of concrete slabs with carbon composite materials based on the finite element model. MATEC Web of Conf., 251, № 04061 (2018)

12. V.T. Erofeev, E.V. Zavalishin, I.V. Rimshin, V.L. Kurbatov, M.V. Stepanovich, Frame composites based on soluble glass. Res. J. of Pharm.1, Biol. and Chem. Scie., 7 (3), pp. 2506-2517 (2016)

13. Y.M. Bazhenov, V.T. Erofeev, V.I. Rimshin, S.V. Markov, V.L. Kurbatov, Changes in the topology of a concrete porous space in interactions with the external medium. Engineering Solid Mechanics, 4 (4), pp. 219-225 (2016)

14. V. Erofeev, V. Kalashnikov, S. Karpushin, A. Rodin, V. Smirnov, O. Smirnova, M. Moroz, V. Rimshin, I. Tretiakov, A. Matvievskiy, Physical and mechanical properties of the cement stone based on biocidal Portland cement with active mineral additive. Solid St. Phen., 871, pp. 28-32 (2016)

15. A. Krishan, V. Rimshin, V. Erofeev, V. Kurbatov, S. Markov, The energy integrity resistance to the destruction of the long-term strength concrete. Proc. Eng., 117 (1), pp. 211-217 (2015)

16. V.D. Antoshkin, V.I. Travush, V.T. Erofeev, V.I. Rimshin, V.L. Kurbatov, The problem optimization triangular geometric line field. Mod. Appl. Scie., 9 (3), pp. 4650 (2015)

17. V.I. Rimshin, E.A. Larionov, V.T. Erofeyev, V.L. Kurbatov, Vibrocreep of concrete with a nonuniform stress state. Life Scie. J., 11 (11), pp. 278-280 (2014)

18. V.I. Telichenko, V.I. Rimshin, A.V. Karelskii, B.V. Labudin, V.L. Kurbatov, Strengthening technology of timber trusses by patch plates with toothed-plate connectors. J. of Ind. Poll. Cont., 33 (1), pp. 1034-1041 (2017)

19. A.L. Krishan, V.L. Rimshin, V.A. Rakhmanov, E.A. Troshkina, V.E. Kurbatov, Bearing capacity of short concrete filled steel tube columns of circular cross-section (2017)

20. A., L. Krishan, V.I. Rimshin, V.I. Telichenko, V.A. Rakhmanov, M.Yu. Narkevich, Practical implementation of the calculation of the bearing capacity trumpet-concrete column (2017)

21. V. Telichenko, V. Rimshin, V. Eremeev, V. Kurbatov, Mathematical modeling of groundwaters pressure distribution in the underground structures by cylindrical form zone. MATEC Web of Conf., 196, № 02025 (2018)

22. A.A. Varlamov, V.I. Rimshin, S.Y. Tverskoi, The modulus of elasticity in the theory of degradation. IOP Conf. Series: Mat. Scie. and Eng., 463 (2), № 022029 (2018)

23. A.A. Varlamov, V.I. Rimshin, S.Y. Tverskoi, Security and destruction of technical systems. IFAC-PapersOnLine, 51 (30), pp. 808-811 (2018) 
24. E. Kuzina, V. Rimshin, Deformation Monitoring of Road Transport Structures and Facilities Using Engineering and Geodetic Techniques. Ad. in Int.nt Syst. and Comp., 692, pp. 410-416 (2018)

25. E. Kuzina, A. Cherkas, V. Rimshin, Technical aspects of using composite materials for strengthening constructions. IOP Conf. Series: Mat. Scie. and Eng., 365 (3), № 032053 (2018)

26. A. Cherkas, V. Rimshin, Application of composite reinforcement for modernization of buildings and structures. MATEC Web of Conf., 117, № 00027 (2017)

27. V. Rimshin, R. Aralov, Sustainable regeneration of urban areas (using the example of Moscow renovation program. E3S Web of Conf., 110, № 01011 (2019)

28. E. Kuzina, V. Rimshin, Experimental and calculated evaluation of carbon fiber reinforcing for increasing concrete columns carrying capacity. E3S Web of Conf., 97, № 04007 (2019)

29. E. Kuzina, V. Rimshin, Strengthening of Concrete Beams with the Use of Carbon Fiber. Ad. in Int. Syst. and Comp., 983, pp. 911-919 (2019)

30. A. Varlamov, V. Rimshin, S. Tverskoi, A method for assessing the stress-strain state of reinforced concrete structures. E3S Web of Conf., 91, № 02046 (2019)

31. V. Rimshin, B. Labudin, V. Morozov, A. Orlov, A. Kazarian, V. Kazaryan, Calculation of Shear Stability of Conjugation of the Main Pillars with the Foundation in Wooden Frame Buildings. Ad. in Int. Syst. and Comp., 983, pp. 867-876 (2019)

32. E. Kuzina, V. Rimshin, V. Kurbatov, The Reliability of Building Structures Against Power and Environmental Degradation Effects. IOP Conf. Series: Mat. Scie. and Eng., 463 (4), № 042009 (2018)

33. N.I. Karpenko, V.A. Eryshev, V.I. Rimshin, The Limiting Values of Moments and Deformations Ratio in Strength Calculations Using Specified Material Diagrams. IOP Conf. Series: Mat. Scie. and Eng., 463 (3), № 032024 (2018)

34. I.L. Shubin, Y.V. Zaitsev, V.I. Rimshin, V.L. Kurbatov, P.S. Sultygova, Fracture of high performance materials under multiaxial compression and thermal effect. Eng. Solid Mech., 5 (2), pp. 139-144 (2017)

35. S.A. Korotaev, V.I. Kalashnikov, V.I. Rimshin, I.V. Erofeeva, V.L. Kurbatov, The impact of mineral Aggregates on the thermal conductivity of cement composites. Ecol., Envir.and Conser., 22 (3), pp. 1159-1164 (2016)

36. A.L. Krishan, E.A. Troshkina, V.I. Rimshin, V.A. Rahmanov, V.L. Kurbatov, Loadbearing capacity of short concrete-filled steel tube columns of circular cross section. Res. J. of Pharmac., Biol. and Chem. Scie., 7 (3), pp. 2518-2529 (2016) 